well-being agenda, therapeutic optimism, preventing revolving doors, early intervention, social inclusion) and, in the words of the author, all that 'brouhaha'. More often than not he was left having to do all the provision himself.

In terms of ideas helpful to services Salmon does offer some insights. He stresses the need to involve carers more effectively when drawing care plans that are feasible and implementable, an awareness that people with schizophrenia are particularly sensitive to defensiveness, insincerity or discomfort in staff and more likely to react in a violent or bizarre manner when faced with uncaring professionals, and the need for straight and frank communication when establishing a prognosis and therapeutic hopes.

Although at times I was uncomfortable at his comments expressing a hint of resentment against other 'creeds and races' (both patients and staff) who often populate admission wards and poor estates, and the deference he showed the medical profession as opposed to other mental health workers, I do agree with the overriding message that we have a long way to go to work alongside carers in a mutually sharing system of care. I would recommend this book for care coordinators and those interested in more responsive and engaged services.

Leonard Fagin Honorary Senior Lecturer, University College London, and Consultant Psychiatrist, South Forest Centre, Leytonstone, London E11 4HU, UK. Email: Ifagin@blueyonder.co.uk

doi: 10.1192/bjp.bp.110.085902

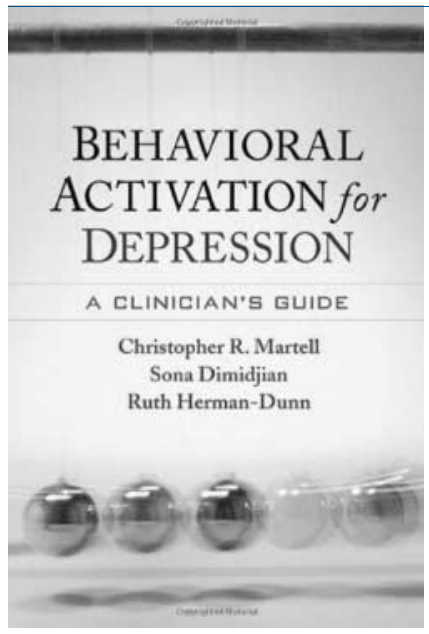

\section{Behavioural Activation} for Depression: A Clinician's Guide

By Christopher R. Martell, Sona Dimidjian

\& Ruth Herman-Dunn Guilford Press. 2010. US\$35.00 (hb). 224pp. ISBN: 9781606235157

As the authors comment in this very accessible book, they are sometimes confronted by the objection that behavioural activation 'sounds too simplistic'. It is indeed a very clear and straightforward model for helping people who experience depression. Nevertheless, coaching a client into accepting that what they need to do in order to feel better in their mood is to begin to identify and indulge in more 'antidepressant behaviours' can be a challenging task; but it is a rewarding one. In fact, for me the great advantage of the model is that it is remarkably easy to follow. For some, of course, this may be its downfall. After all, is a psychological therapy not supposed to be complicated to learn, couched in mystifying language and (these days anyway) contain the word 'cognitive' in its title?

Behavioural activation starts from the premise that in order to feel better it is necessary to 'act' better; that mood and activity are inextricably related to each other; that as a person becomes more depressed they stop engaging in activities that were once pleasurable, utilise escape or avoidance behaviours which service to keep them stuck in a rut, such as shutting themselves away in their room and not answering the phone; pull away from their world and potential sources of antidepressant reinforcement, and as a consequence feel more down. Behavioural activation really works, as the authors have demonstrated in their research, and there is evidence that it is as effective as 'full' cognitive-behavioural therapy. It is now in the National Institute for Health and Clinical Excellence guidance for depression. It is being increasingly used, as I know first-hand, as a front-line therapy by workers in primary care mental health. As a client of the authors once very succinctly put it: 'So are you saying that cognitive therapists believe that the head teaches the hands, whereas the BA (behavioural activation) approach assumes that the hands teach the head?' That is a great way of describing something which is essentially a very practical way of learning how to feel better.

Linda Gask Professor of Primary Care Psychiatry National Primary Care Research and Development Centre, 5th Floor, Williamson Building, University of Manchester, Oxford Road, Manchester M13 9PL. Email: Linda.Gask@manchester.ac.uk

doi: 10.1192/bjp.bp.110.080192

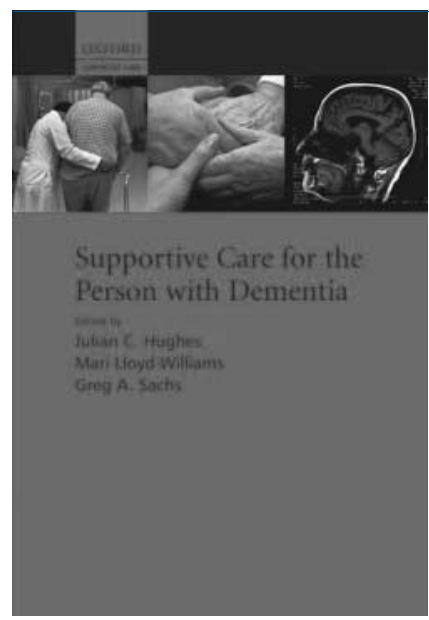

\section{Supportive Care for the Person with Dementia}

Edited by Julian Hughes, Mari Lloyd-Williams \& Greg Sachs. Oxford University Press. 2009. f59.95 (hb). 330pp. ISBN: 9780199554133

This is a book covering the care for people with dementia, from diagnosis to death. The 'supportive care' of the title refers to a model developed to guide the comprehensive support of people with a variety of long-term, life-shortening conditions. The approach owes a lot to the philosophy of palliative care in its attention to biological, psychological, social and spiritual needs but these considerations are extended, within supportive care, to encompass diagnosis, curative and life-prolonging treatments as well as palliation and dying. The book itself is one of a series of volumes focused on different diseases and is the first to apply this framework to dementia.

One of the delights of the book is the range of writings, with no fewer than 32 chapters packed into its 300 or so pages, including many contributions from well-known names as well as some newer voices. There are chapters from psychiatrists and old age physicians, general practitioners and palliative care specialists, psychologists, philosophers and many more besides. The mix is greatly enriched by contributions from individuals with dementia and family members of people with dementia, as well as chapters on often neglected topics such as Huntington's dementia and dementia in low-income countries. Overall the content 